Research Article

\title{
Financing Target and Product Line Design on the Flexible and Fixed Reward Crowdfunding
}

\author{
Xiaofeng Liu $\mathbb{D}^{1},{ }^{1}$ Hong Zhang, ${ }^{1}$ Nannan $\mathrm{Xi}^{2}$ and Hamari Juho ${ }^{2}$ \\ ${ }^{1}$ School of Business Administration, Zhongnan University of Economics and Law, Wuhan 430073, China \\ ${ }^{2}$ Gamification Group, Tampere University, Kalevantie 4, 33100 Tampere, Finland \\ Correspondence should be addressed to Xiaofeng Liu; z0003827@zuel.edu.cn
}

Received 10 October 2019; Revised 31 January 2020; Accepted 28 February 2020; Published 26 March 2020

Academic Editor: Marcello Pellicciari

Copyright (C) 2020 Xiaofeng Liu et al. This is an open access article distributed under the Creative Commons Attribution License, which permits unrestricted use, distribution, and reproduction in any medium, provided the original work is properly cited.

This study examined the product line design under two different types of reward crowdfunding, namely, the fixed and the flexible reward crowdfunding. To investigate different effects of the two different reward crowdfunding mechanisms, we addressed the problem of product and pricing decisions in reward crowdfunding by incorporating individual rationality and incentive compatibility into different funding modes. Specifically, when the creator designed the menu price, we compared the menu design, which includes price and quality between the product line under two different crowdfunding mechanisms. We found that when the quality was exogenous, the project could have higher success rate and get more expected profit under the fixed reward crowdfunding than that under the flexible reward crowdfunding; however, the creator could set a higher target and a larger price discrepancy under the flexible reward crowdfunding in some specific market condition. Then, we extended to the situation where the quality was endogenous and found the similar results as the quality was exogenous. Interestingly, the quality differentiation of the product line under the flexible reward crowdfunding is much more than that under the fixed reward crowdfunding. These results can provide the guideline and suggestion to help the creators design their product line, set the target, and select the suitable modes between the fixed and the flexible reward crowdfunding.

\section{Introduction}

With the advent of new Internet-based crowdfunding, increasing number of innovative ideas and projects have been financially supported by mass investors, which eventually accelerate technological innovation and industrial transformation. According to the forecasting of Statista Market, the transaction value is expected to show an annual growth rate (CAGR 2019-2023) of 14.7\%, resulting in the total amount of US $\$ 11,985.6 \mathrm{~m}$ by 2023 . There are actually four main categories of crowdfunding, such as the reward-based, donation-based, lending-based, and equity-based crowdfunding [1]. In the market, reward-based crowdfunding is the most popular, which has been a source of funding especially for small businesses to kickstart the creation of new projects and products.

There are mainly two types of reward-based crowdfunding: the fixed mode (or All-or-Nothing) and the flexible mode (or Keep-it-All). In the fixed mode, a crowdfunding project creator receives the pledged fund and starts the project only if the funding target is met at the end of the campaign, but receives nothing and cancels the project otherwise. Conversely, in the flexible mode, the founders of crowdfunding campaign keep the raised fund regardless whether the total amount of pledged fund reaches the funding target or not. Among the global crowdfunding platforms, Kickstarter, the largest crowdfunding platform, adopts the fixed mechanism, while its largest competitor, Indiegogo, allows both the fixed and the flexible funding mechanisms. As for the founders, how to make the crowdfunding campaign successful according to different reward-based mechanisms has become a challenge. For example, the success rate on Kickstarter is $34 \%$ and is only $17 \%$ on Indiegogo [2]. In this study, we aim at understanding how to choose between the fixed and flexible modes based on the financial target and the specific market conditions. 
The different funding modes will have different effects on project performance. For example, Ubuntu Edge, a smartphone announced by Canonical, launched on Indiegogo on July 22, 2013, with fixed funding. However, it failed to reach the target of $\$ 32$ million in the end. It is widely believed that the project would have succeeded if the flexible funding mechanism was chosen. To investigate the different effects of the two different funding modes in reward crowdfunding, we addressed the problem of product line and pricing strategy in reward crowdfunding by considering individual consumer's rationality and incentive compatibility. Specifically, we compared two product line designs in the fixed funding mode and the flexible funding mode: (1) a design that motivates a high-type consumer to sign up a high-type product when facing no risk of project failure and (2) a design that motivates her to sign up a low-type product when facing no risk of project failure. We found that the price discrepancy and the optimal target under the flexible mechanism in some specific area were larger than those under the fixed mechanism, while the expected profit and the success rate were lower; then, we extended to the situation where the quality was endogenous and found similar results where the quality was exogenous. Interestingly, under the flexible reward crowdfunding, the product line had much more quality differentiation than the product line under the fixed reward crowdfunding when the quality was endogenous. With the new findings and related discussions, our study contributes not only to the stream of the literature on product line decisions but also to the growing literature on crowdfunding. More importantly, our findings provide important practical implications for entrepreneurs to optimize their product line design and choose an optimal pricing strategy in different crowdfunding mechanisms in order to get the financial target.

The rest of this paper is organized as follows. In Section 2 , we review the previous studies related to product line design and crowdfunding; then, we further describe the model and analyze the creator's optimal pricing strategy under the two mechanisms when the quality is exogenous in Section 3. In Section 4, we extend the basic model to the situation that quality is endogenous and compare the difference of target and optimal pricing strategy under the two mechanisms. Based on the findings, the conclusion and discussion are presented in Section 5.

\section{Literature Review}

This study is relevant to two steams of the literature. We provide a brief and noncomprehensive review. The first stream of the literature is the product line design. Mussa and Rosen [3] and Moorthy [4] are pioneers who studied how firms use the second-degree price discrimination to motivate consumer self-selection among vertically differentiated products. In Moorthy's framework [5], the downward quality distortion came from the low-quality product and found no distortion at-the-top. In order to prevent high-type consumers from deviating to low-type products, firms had to set lower quality for the low-price product. Subsequent papers studying the product line design also incorporated distribution consideration [6], the presence of private information [7], price competition [8,9], consumer deliberation [10], and store [11]. Hu et al. [12] discussed the optimal product line design in the fixed crowdfunding in which consumers were motivated to overpay to ensure project's success. Thus, it has long been believed that the reward crowdfunding can generate more expected profit by using the fixed mode. However, Bi et al. [13] examined the two different types of crowdfunding mechanisms in a single product situation and found that the fixed and the flexible funding modes both had their own strengths in different situations. When project creators in the reward-based crowdfunding provided a line of product with different qualities and prices to match different consumer preferences, the pricing and quality decisions could be more complicated in the product line than in a single product circumstance. The high-type consumers could select lowtype quality products with unsuitable price dispersion and quality differentiation in the product line. In view of this, how to set the financing target and design the product line between the two different modes of reward crowdfunding is an interesting topic that deserves further exploration. In this study, we will try to compare the fixed and flexible funding modes in the product line situation and subsequently guide the creators in their choices of different modes.

In addition, this study also relates to the literature on mechanism design of crowdfunding. Because of the information asymmetry, moral hazard problem and adverse selection can happen in crowdfunding activities. Strausz [14] considered a moral hazard problem where consumers were uncertain whether the creator actually delivered the rewards or run away with the money raised from the campaign. Strausz [14] found that a deferred payment to the creator could alleviate the moral hazard problem. Chemla and Katrin [15] compared the fixed funding with the flexible funding in the presence of similar moral hazard issues and showed that the fixed funding is more efficient than the flexible funding and made contributors reveal their preferences for the product truthfully. In order to focus on the learning function of fixed funding mechanism, they abstract from the creator's product line design and making a simplifying assumption that a single product is offered to consumers and leave the product line design problem for further study. Empirically, authors in [16-18] investigated the role that the choice of funding mechanism has on the project outcomes on Indiegogo and finds that projects that select the AON have a higher probability of success due to reducing uncertainty for potential contributors. Marwell [19] used a structural model to study how different funding mechanisms affect creators and fundraisers' incentives in crowdfunding markets.

There is much difference of this study compared with $[12,13]$ : first, different from [12], under the flexible crowdfunding, the consumer might face more risk than under the fixed crowdfunding because their bids are sunk if the project fails in the end. Thus, the incentives of both the creator and the consumers can be different, which will have a great effect on the product line design; second, different from [13], we used the same classical utility function to model the 
consumers expected utility without assuming that the two types of crowdfunding have different trust levels. We found the quality need not be always higher in the flexible mode than in the fixed mode. In fact, we found that the highquality product in the fixed mode is the same as the product offered in the flexible mode in some situation; third, by comparing the difference of the product line design under the two crowdfunding mechanism from the perspective of price discrepancy, quality differentiation, target setting, success rate, and expected profit, it is helpful for the creator to choose between the two alternatives, while in [13], only one single product is being considered.

\section{Product Line Strategy When the Quality Is Exogenous}

3.1. Product Line Strategy under the Flexible Mechanism. We first briefly describe a two-period model based on [12]. At the beginning of the crowdfunding project, a risk-neutral and profit maximizing creator posts a proposed project, with specific information about product quality $(Q)$, price $(P)$, and funding target $(T)$, on a flexible or fixed reward-based crowdfunding platform. There are two periods for consumers to sign up. In each period, one representative and rational consumer $\left(B_{t}, t=1,2\right)$ arrives at the project and makes her sign-up decision. The crowdfunding project starts if and only if consumers from both periods sign up and the pledged fund reaches the preannounced target. Under the flexible crowdfunding, the entrepreneurial firm can keep the entire pledged amount, regardless of whether or not the stated capital raising goal is reached [13], while under the fixed mode, the entrepreneurial firm keeps the money they raised only if the collected funding reaches or exceeds their funding goal. In both mechanisms, the entrepreneur commits to implement the project if and only if at least $T$ dollars are collected [11]. Also, some empirical papers compared the flexible and the fixed mode which mentioned that the consumer assumed the risk under the flexible mode while the creator assumed the risk under the fixed mode if the goal could not be reached $[2,19]$. So, we assume that the consumer will get nothing and lose her bid if the goal cannot be reached in the flexible mechanism. To model consumer heterogeneity on product valuation, consumer types are assumed to be independently and identically distributed with a two-point distribution: a high-type consumer $(H)$ with probability $\alpha$ and a low-type consumer $(L)$ with probability $1-\alpha$, where $H>L>0$. Consumer $B_{1}$, appearing in period 1, makes a sign-up decision based on her private product valuation, specific product offerings, and expected success rate of the project. The creator then publishes the purchase decision of consumer $B_{1}$ online. Next, consumer $B_{2}$, arriving at the project in period 2 and realizing her private product evaluation, observes the decision of $B_{1}$ and makes a purchase decision to maximize her own expected utility. With the menu strategy, the creator posts a menu $\left(P_{L}, P_{H}\right)$, where $P_{L} \leq L \leq P_{H} \leq H$. The target is $T=P_{L}+P_{H}$. From the individual rationality and incentive compatibility condition, if $B_{1}$ is a high-type consumer, then she will bid $P_{H}$ with the condition:

$$
H-P_{h} \geq \alpha\left(H-P_{L}\right)-(1-\alpha) P_{L} \geq 0 .
$$

If $B_{1}$ is a low-type consumer, then she will bid $P_{l}$ with the condition:

$$
\alpha\left(L-P_{L}\right)-(1-\alpha) P_{L} \geq 0 .
$$

Thus, the project can be successful in the following situations: (1) $B_{1}$ is a low-type consumer and she will sign up at a low price; $B_{2}$ is a high-type consumer and she will sign up at a high price; $B_{1}$ is a high-type consumer and she will sign up at a high price; $B_{2}$ will always sign up at a low price regardless of her type; (2) $B_{1}$ is a low-type consumer and she will sign up a low price; $B_{2}$ is a high-type consumer and she will sign up at a high price; $B_{1}$ is a high-type consumer and she will sign up at a low price, $B_{2}$ will sign up a high price when she is a high-type consumer; (3) $B_{1}$ is a low-type consumer and she will not bid; $B_{1}$ will sign up at a high price when she is a high-type consumer, and $B_{2}$ will sign up a low price; (4) $B_{1}$ is a low-type consumer and she will not bid; $B_{1}$ is a high-type consumer and will sign up at a low price, and $B_{2}$ will sign up at high price when she is a high-type consumer (Figure 1).

By comparing the expected profit of each situation above, the optimal menu pricing can be designed as follows.

Proposition 1. Under the flexible crowdfunding, when the quality is exogenous, the optimal menu price should be designed as follows:

(i) Area $I: \quad \alpha \in(0,(3-\sqrt{5}) / 2] ; \quad$ or $\quad \alpha \in((3-$ $\sqrt{5}) / 2,2 / 3], \quad H / L \leq\left(3 \alpha-2 \alpha^{2}\right) /\left(3 \alpha-\alpha^{2}-1\right) ; \quad$ or $\alpha \in((3-\sqrt{5}) / 2,0.5], 1 \leq H / L \leq 2$; or $\alpha \in(0.5,1]$, $H / L \leq\left(4 \alpha-2 \alpha^{2}-1\right) /\left(3 \alpha-\alpha^{2}-1\right)$ the optimal menu is $\left(P_{L}, P_{H}\right)=(\alpha L,(1-\alpha) H+\alpha L)$

(ii) Area II: $\alpha \in((3-\sqrt{5}) / 2,2 / 3]$ and $H / L \geq$ $\left(3 \alpha-2 \alpha^{2}\right) /\left(3 \alpha-\alpha^{2}-1\right) ;$ or $\alpha \in(2 / 3,1), \quad H / L \geq$ $(2-\alpha) / \alpha$, and the optimal menu is $\left(P_{L}, P_{H}\right)=$ $(\alpha L, H)$

(iii) Area III: $\alpha \in(0.5,2 / 3], \quad 1 / \alpha \leq H / L \leq 2$; or $\alpha \in(2 / 3,1), 1 / \alpha \leq H / L \leq(2-\alpha) / \alpha$, and the optimal menu is $\left(P_{L}, P_{H}\right)=(L,(1-\alpha) H+L)$

(iv) Area IV: $\alpha \in(0.5,1]$ and $\left(4 \alpha-2 \alpha^{2}-1\right) /$ $\left(3 \alpha-\alpha^{2}-1\right) \leq H / L \leq 1 / \alpha$, and the optimal menu is $\left(P_{L}, P_{H}\right)=(L, H)$

Proof. Please refer to the Appendix.

Proposition 1 indicates that the crowdfunding creator's optimal menu price depends on specific market condition. As shown in Figure 2, Proposition 1 identifies four market conditions under which the creator offers a different optimal menu price.

Proposition 1 indicates that when the fraction of hightype consumer is low, the creator should set a lower price $\alpha L$ and make sure the first consumer signs up in order to improve the success rate of the project. At the same time, as long as the high price is low enough to satisfy the incentive compatible condition, the high-type consumer will sign up 


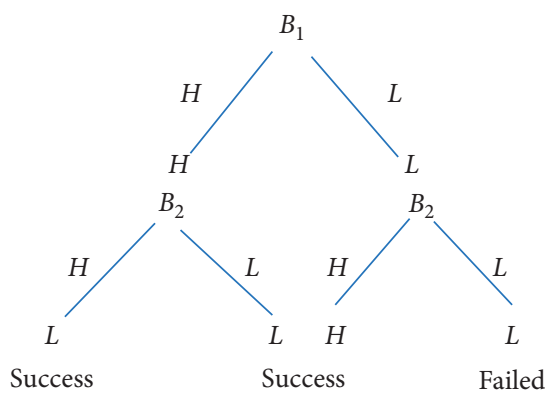

(1)

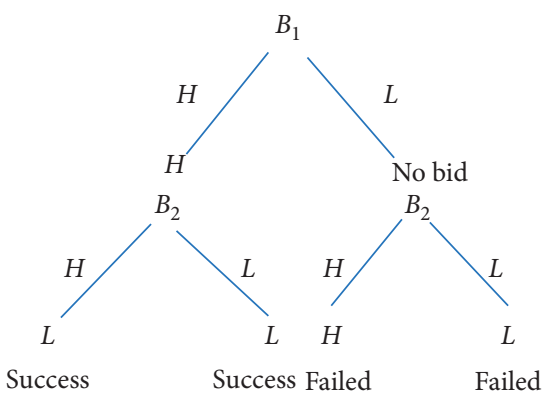

(3)

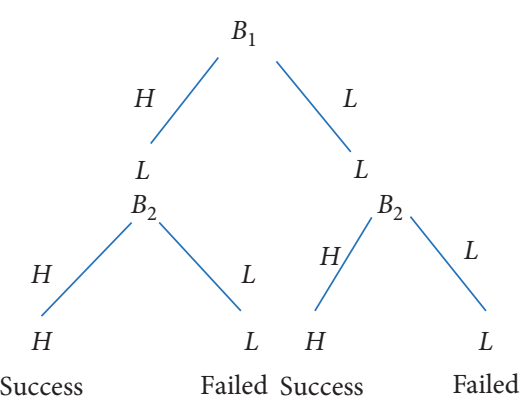

(2)

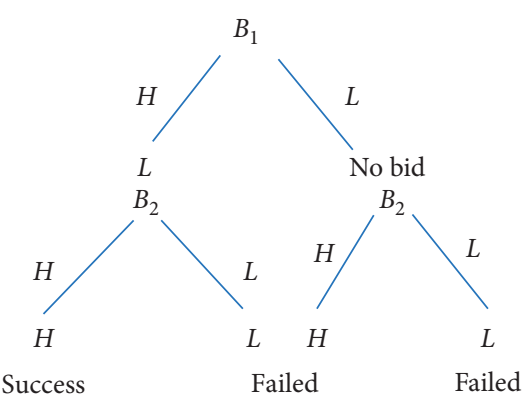

(4)

Figure 1: The backward induction with four different situations.

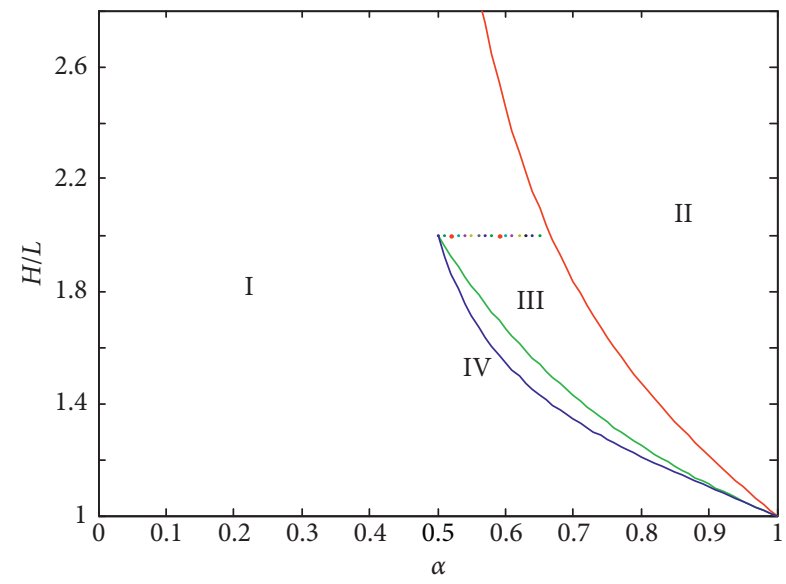

Figure 2: Optimal menu pricing under the flexible crowdfunding.

at a high price even with a low price option; when the fraction of high-type consumer is in the middle and the heterogeneity of the consumer is low, the creator can increase the low price from $\alpha L$ to $L$ and the high price from $(1-\alpha) H+\alpha L$ to $(1-\alpha) H+L$ in order to improve the profit; with the fraction of high-type consumer increasing and when the heterogeneity of the consumer is high enough, the creator can even set the highest price $H$ to obtain all the surplus of the second consumer and set a lower price $\alpha L$ to ensure that the first consumer will bid which can increase the success rate and the expected profit of the project.

3.2. Product Line Strategy under the Fixed Mechanism. With the similar analysis as in 3.1, from individual rationality and incentive compatibility, if $B_{1}$ is a high-type consumer, then she will bid $P_{H}$ with the following condition:

$$
H-P_{h} \geq \alpha\left(H-P_{L}\right) \geq 0 .
$$

If $B_{1}$ is a low-type consumer, then she will bid $P_{l}$ because $L-P_{L} \geq 0$. Thus, the optimal menu pricing can be designed as follows.

Lemma 1. Under the fixed crowdfunding, when the quality is exogenous, the optimal menu price is $\left(P_{L}, P_{H}\right)=$ $(L, H-\alpha(H-L))$.

By Proposition 1 and Lemma 1, we can see the difference of the product line design when the quality is exogenous under the fixed and the flexible modes from the perspective of success rate, optimal target, and expected profit, as shown in Table 1.

By comparison the success rate, the optimal target, and the expected profit between the fixed and the flexible modes as shown in Table 2, we can get Proposition 2:

Proposition 2. When the quality is exogenous, the success rate and the expected profit of the project are higher under the fixed mechanism, but the target and the price discrepancy are larger under the flexible mechanism.

Proof. Please refer to the Appendix.

Proposition 2 indicates that, for a given product quality, the fixed mechanism is better than the flexible mechanism from the perspective of the success rate and the expected profit, but the creator can set a higher target and price under the flexile mechanism in some specific areas. The price discrepancy is also larger under the flexible mechanism, which means the overpaying effect of high-type consumers $((1-\alpha) H, H-\alpha L, H-L)$ is always larger than the overpayment $((1-\alpha)(H-L))$ under the fixed crowdfunding. 
Table 1: Product line under the fixed and the flexible modes when quality is exogenous.

\begin{tabular}{|c|c|c|c|c|c|}
\hline \multicolumn{2}{|c|}{ Mechanism } & Menu price & Target & Success rate & Expected profit \\
\hline Fixed & & $(L, H-\alpha(H-L))$ & $(1-\alpha) H+(1+\alpha) L$ & $\alpha(2-\alpha)$ & $\left(2 \alpha-\alpha^{2}\right)((1-\alpha) H+(1+\alpha) L)$ \\
\hline Flexible & $\begin{array}{l}\text { Area I } \\
\text { Area II } \\
\text { Area III } \\
\text { Area IV }\end{array}$ & $\begin{array}{c}(\alpha L, H-\alpha(H-L)) \\
(\alpha L, H) \\
(L,(1-\alpha) H+L) \\
(L, H)\end{array}$ & $\begin{array}{c}(1-\alpha) H+2 \alpha L \\
\alpha L+H \\
(1-\alpha) H+2 L \\
H+L\end{array}$ & $\begin{array}{c}\alpha(2-\alpha) \\
\alpha \\
\alpha \\
\alpha\end{array}$ & $\begin{array}{c}\left(\alpha^{3}-3 \alpha^{2}+2 \alpha\right) H+2 \alpha^{2}(2-\alpha) L \\
\alpha H+\alpha^{2} L \\
\left(\alpha-\alpha^{2}\right) H+2 \alpha L \\
\alpha(H+L)\end{array}$ \\
\hline
\end{tabular}

TABle 2: Product line comparison between the fixed and the flexible modes when quality is exogenous.

\begin{tabular}{|c|c|c|c|c|}
\hline Scope & Menu price & Target & Success rate & Expected profit \\
\hline Area I & $p_{l}^{a o n}>p_{l}^{k i a}, p_{h}^{a o n}=p_{h}^{k i a}$ & $T^{a o n}>T^{k i a}$ & $\operatorname{Pr}^{a o n}=\operatorname{Pr}^{k i a}$ & $\Pi^{a o n}>\Pi^{k i a}$ \\
\hline Area II & $p_{l}^{a o n}>p_{l}^{k i a}, p_{h}^{a o n}<p_{h}^{k i a}$ & $T^{a o n}<T^{k i a}$ & $\operatorname{Pr}^{a o n}>\operatorname{Pr}^{k i a}$ & $\Pi^{a o n}>\Pi^{k i a}$ \\
\hline Area III & $p_{l}^{a o n}=p_{l}^{k i a}, p_{h}^{a o n}<p_{h}^{k i a}$ & $T^{a o n}<T^{k i a}$ & $\operatorname{Pr}^{a o n}>\operatorname{Pr}^{k i a}$ & $\Pi^{a o n}>\Pi^{k i a}$ \\
\hline Area IV & $p_{l}^{a o n}=p_{l}^{k i a}, p_{h}^{a o n}<p_{h}^{k i a}$ & $T^{a o n}<T^{k i a}$ & $\operatorname{Pr}^{a o n}>\operatorname{Pr}^{k i a}$ & $\Pi^{a o n}>\Pi^{k i a}$ \\
\hline
\end{tabular}

Thus, only when the high-type consumer has more overpayment incentive can the project in the flexible mechanism be successful, especially when the fraction of high-type consumer is high or when the heterogeneity of the consumers is high. The main reason is that the consumers will take much more risk under the flexible mode than under the fixed mode. The high-type consumer will pay more to ensure the success of the project.

\section{Product Line Strategy When Quality Is Endogenous}

In this section, we extend the base model and allow the creator to offer two vertically differentiated products. For a quality level $Q$, a high-type consumer's product valuation is $V_{h}=H Q_{h}$ and a low-type consumer's product valuation is $V_{l}=L Q_{l}$, where $H>L>0$. Following the previous literature (e.g., Guo and Zhang [9]), we assume the unit product cost of a good with quality level $Q$ is $Q^{2} / 2$. The fixed cost of the proposed project is assumed to be 0 for the convenience. When the product quality is exogenous, a high-type consumer $B_{2}$ faces no risk of project failure if she observes that consumer $B_{1}$ has pledged $p_{h}^{M}$ because the project can always start no matter which product she signs up for. However, when the creator is allowed to offer vertically differentiated products and endogenously determines their qualities, a high-type consumer does not always prefer $p_{l}^{M}$ to $p_{h}^{M}$ when facing no risk of project failure because the surplus of signing up at $p_{l}^{M} H Q_{l}-p_{l}^{M}$ is not necessarily always larger than the surplus of signing up at $p_{h}^{M}, H Q_{h}-p_{h}^{M}$. As a consequence, if $B_{1}$ has pledged at $p_{h}^{M}$, a rational high-type consumer $B_{2}$ will either sign-up at $p_{l}^{M}$ or $p_{h}^{M}$ depending on whether or $H Q_{l}-p_{l}^{M} \geq H Q_{h}-p_{h}^{M}$ when vertically differentiated product qualities are endogenized.

4.1. Product Line Strategy under the Flexible Mechanism. With the menu price, the creator posts a menu containing a high price $p_{h}^{M}$ and a low price $p_{l}^{M}$, where $p_{l}^{M} \leq L Q_{l}<p_{h}^{M} \leq H Q_{h}$. The target is $T=p_{l}^{M}+p_{h}^{M}$. From the individual rationality and incentive compatibility conditions, if $B_{1}$ is a high-type consumer, then she will sign up $p_{h}^{M}$ with the following condition:

$$
H Q_{h}-P_{h} \geq \alpha\left(H Q_{h}-P_{L}\right)-(1-\alpha) P_{L} \geq 0 .
$$

If $B_{1}$ is a low-type consumer, then she will bid $p_{l}^{M}$ with the following condition:

$$
\alpha\left(L Q_{h}-P_{L}\right)-(1-\alpha) P_{L} \geq 0 .
$$

Similar to Proposition 1, when the quality is endogenous, the optimal menu pricing under the flexible mechanism can be obtained as follows.

Proposition 3. The creator can set the target as $T=H^{2}$ and offers only the high-quality product $\left(P_{h}^{M}, Q_{h}^{M}\right)=\left(H^{2}, H\right)$.

Proof. Please refer to the Appendix.

Different form Proposition 1, when the product quality is endogenous, Proposition 3 indicates that the creator has to set a lower target in the flexible mechanism because of the higher perceived risk of the consumer. The creator only provides the high-quality product and targets high-type consumers. The reason is that if the low quality is provided, the creator has to decrease $p_{h}^{M}$ to ensure the high-type consumer not to deviate from choosing high-quality product. The benefit from getting a low-type consumer cannot compensate for the loss from a high-type consumer's deviation to a low-type product. Thus, the creator has to set a lower target and offers only the high-quality product.

4.2. Product Line Strategy under the Fixed Mechanism. From the individual rationality and incentive compatibility conditions, if $B_{1}$ is a high-type consumer, then she will sign up $p_{h}^{M}$ with the condition:

$$
H Q_{h}-P_{h} \geq \alpha\left(H Q_{h}-P_{L}\right) \geq 0 .
$$

If $B_{1}$ is a low-type consumer, then she will bid $p_{l}^{M}$ with the condition:

$$
L Q_{h}-P_{L} \geq 0
$$


Similar to Proposition 1, when the quality is endogenous, the optimal menu pricing under the fixed mechanism can be obtained as follows.

Proposition 4. The creator can set the optimal menu price under the fixed crowdfunding:

(1) Area I: $H / L \geq 1 / \alpha$, the optimal menu design is $\left(Q_{h}^{M}, P_{h}^{M}\right)=\left(H, H^{2}\right)$

(2) Area $I I: 1 \leq H / L<1 / \alpha$, the optimal menu design is $\left(Q_{h}^{M}, P_{h}^{M}\right)=\left(H, H^{2}-\alpha(H-L) \Delta 1\right)$ and $\left(Q_{l}, P_{l}\right)=$ $\left(\Delta_{2}, \Delta_{2} L\right)$, where $\Delta_{1}=L+(L-H) / 1-\alpha$ and $\Delta_{2}=L-\alpha(H-L)$

Proof. Please refer to the Appendix.

Proposition 4 indicates that the crowdfunding creator's optimal menu strategy depends on specific market condition. As shown in Figure 3, Proposition 4 identifies two market conditions under which the creator offers a different optimal menu design.

Without the access to the private information of each consumer's quality valuation, the creator cannot conduct a perfect price discrimination. To discourage a high-type consumer from signing up a low-type product in this case, the creator must distort product quality levels downward. We find $Q_{h}^{M}=H$, a famous "no distortion at-the-top" result [4]. With the finding that $Q_{l}^{M}<L$, the downward quality distortion comes from the low-type product. The downward distortion benefits the creator by preventing a high-type consumer from signing up at $p_{l}^{M}$. However, this product design strategy comes at a cost for the creator with a lower price being charged on the low-type product and therefore less profit from the low-type consumer.

Similar to Proposition 2, by comparing the success rate, the optimal target, and the expected profit, as shown in Table 3, between the fixed and flexible modes when the quality is endogenous, we can get the following proposition.

Proposition 5. When the quality is endogenous, if the heterogeneity and the fraction of high-type consumer are large (area I), the target, success rate and the expected profit are the same; in area II, the success rate and the expected profit are higher under the fixed mechanism; however, the target, the price discrepancy, and the quality differentiation are larger under the flexible mechanism.

As shown in Table 4, Proposition 5 indicates that when the quality is endogenous, in some areas, the fixed mechanism and the flexible mechanism can get the same success rate and the expected profit, but when the heterogeneity or the fraction of high-type consumer is low enough, the fixed mechanism can get higher profit than the flexible mechanism. The price discrepancy and the product quality differentiation are also larger under the flexible mechanism, which is similar as the product is exogenous.

In Kickstarter, the platform only provides fixed mode. While in Indiegogo, the platform can provide fixed mode

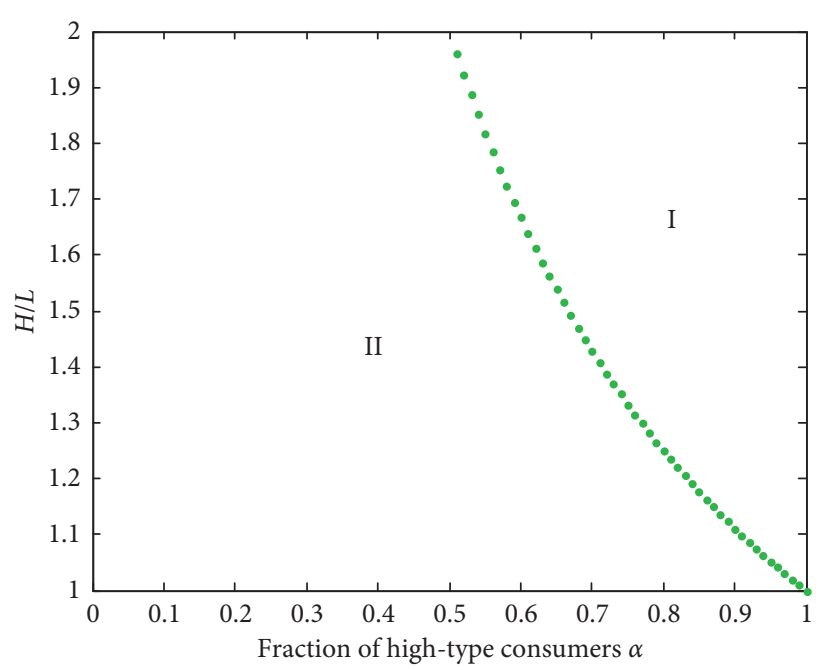

Figure 3: Optimal Product Line Design with different Values of $\alpha$ and $H / L$ in the fixed crowdfunding.

and flexible mode for the creators. In fact, our model can provide a guideline for the creators when they plan to launch a project with different mechanisms. From Proposition 5, we can get the following figure which shows the profit comparison between the fixed mode and the flexible mode if the target is the same when the creator use menu pricing (Figure 4).

This figure is consistent with our main result that the fixed mechanism can get higher profit than the flexible mechanism when the heterogeneity of the consumer $(H / L)$ is low or when the fraction of high-type consumer is low; on the other hand, when the heterogeneity of the consumer $(\mathrm{H} /$ $L)$ is high or when the fraction of high-type consumer is high, the fixed mechanism and the flexible mechanism can get the same profit under menu pricing strategy.

\section{Conclusion}

Crowdfunding provides an alternative way for funding entrepreneurial ventures. As an emerging business model, it may also affect the entrepreneurs' product and pricing decisions differently under different crowdfunding mechanisms. When deciding whether to use crowdfunding, the creator should decide which type of fundraising mechanism to be used. This study provides a theoretical model by investigating how the different mechanisms affect the creator's target setting and optimal pricing strategy in the product line design.

The main finding was that the success rate and the expected profit of the project were higher under the fixed mechanism, while the target and the price discrepancy were larger under the flexible mechanism in some condition. Specially, the quality differentiation was larger under the flexible mechanism when the quality is endogenous. Our findings and related discussions provide practitioners helpful insights about product design and pricing decisions in different crowdfunding mechanisms. As firms turn to crowdfunding market to introduce a new product, it is 
TABle 3: Product line under the fixed and the flexible modes when quality is endogenous.

\begin{tabular}{|c|c|c|c|c|c|}
\hline \multicolumn{2}{|c|}{ Mechanism } & Menu price & Target & $\begin{array}{l}\text { Success } \\
\text { rate }\end{array}$ & Expected profit \\
\hline \multirow[b]{2}{*}{$\mathrm{AON}$} & Area I & $\left(H^{2}, H\right)$ & $H^{2}$ & $\alpha$ & $\alpha H^{2}$ \\
\hline & $\begin{array}{l}\text { Area } \\
\text { II }\end{array}$ & $\begin{array}{c}\left(L \Delta_{2}, \Delta_{2}\right) \\
\left(H^{2}-\alpha(H-L) \Delta_{2}, H\right)\end{array}$ & $H^{2}-(\alpha H-(1+\alpha) L) \Delta_{2}$ & $\alpha(2-\alpha)$ & $\left(\alpha-\left(\alpha^{2} / 2\right)\right)\left(\left(1+\alpha^{2}\right) H^{2}-2\left(\alpha+\alpha^{2}\right) H L+(1+\alpha)^{2} L^{2}\right)$ \\
\hline KIA & & $\left(H^{2}, H\right)$ & $H^{2}$ & $\alpha$ & $\alpha H^{2}$ \\
\hline
\end{tabular}

Table 4: Product line comparison between the fixed and the flexible modes when quality is endogenous.

\begin{tabular}{lccccc}
\hline Scope & Menu price & Quality & Target & Success rate & Expected profit \\
\hline Area I & $P_{H}^{a o n}=P_{H}^{k i a}$ & $Q_{H}^{a o n}=Q_{H}^{k i a}$ & $T^{a o n}=T^{k i a}$ & $\operatorname{Pr}^{\text {aon }}=\operatorname{Pr}^{\text {kia }}$ & $\Pi^{\text {aon }}=\Pi^{\text {kia }}$ \\
Area II & $P_{L}^{a o n}>P_{L}^{k i a} P_{H}^{\text {aon }}<P_{H}^{k i a}$ & $Q_{L}^{a o n}>Q_{L}^{k i a} Q_{H}^{a o n}=Q_{H}^{k i a}$ & $T^{a o n}<T^{k i a}$ & $\operatorname{Pr}^{\text {aon }}>\operatorname{Pr}^{\text {kia }}$ & $\Pi^{\text {aon }} \geq \Pi^{\text {kia }}$ \\
\hline
\end{tabular}

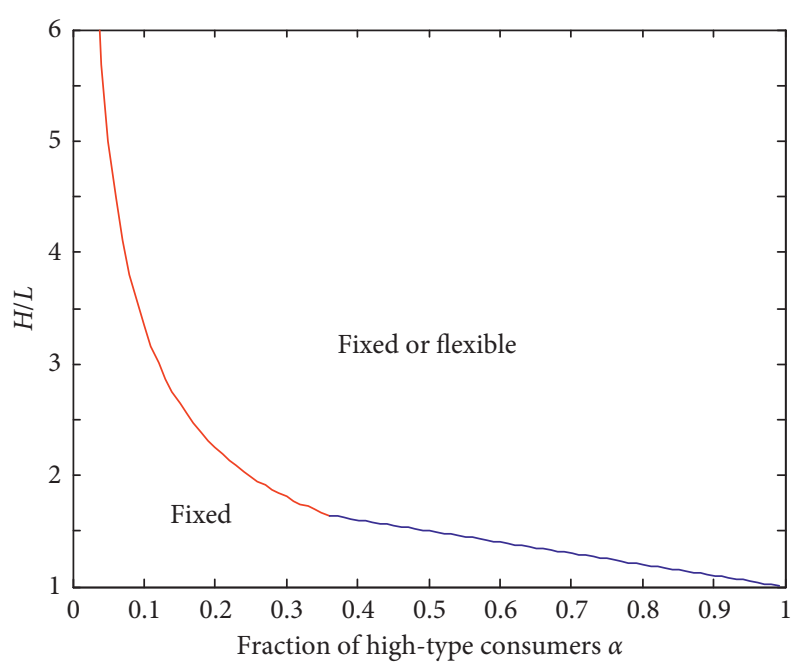

Figure 4: Optimal choice of crowdfunding mechanism.

crucial to understand the factors that influence market outcomes.

It is plausible that a number of limitations could have influenced the results obtained. First, we restricted our analysis to representative investors arriving sequentially in two periods, which can be extended to the setting in which multiple investors arrive sequentially. Second, our analysis was restricted to the menu pricing mechanism, whereas other pricing is used in practice, such as the intertemporal pricing, introduced by $\mathrm{Hu}$ et al. [12]. Lastly, we analyzed the product line design in the complete information situation, and the information disclosure strategy is an interesting topic during the crowdfunding process in an incomplete information situation.

\section{Appendix}

\section{Proof of Proposition 1}

(1) $B_{1}$ is a low-type consumer and she will sign up at a low price; $B_{2}$ is a high-type consumer and she will sign up at a high price; $B_{1}$ is a high-type consumer and she will sign up at a high price; $B_{2}$ will always sign up at a low price regardless of her type.
Form the incentive and compatibility condition:

$$
\begin{aligned}
& \alpha\left(L-P_{L}\right)-(1-\alpha) P_{L} \geq 0 \\
& H-P_{H} \geq \alpha\left(H-P_{L}\right)-(1-\alpha) P_{L} .
\end{aligned}
$$

Thus, $P_{L} \leq \alpha L, P_{H} \leq(1-\alpha) H+\alpha L$. The expected profit is

$$
\begin{aligned}
\pi_{K I A}^{M 1}= & {\left[\alpha^{2}+2 \alpha(1-\alpha)\right]\left(P_{H}+P_{L}\right)=\left(\alpha^{3}-3 \alpha^{2}+2 \alpha\right) H } \\
& +\left(4 \alpha^{2}-2 \alpha^{3}\right) L .
\end{aligned}
$$

(2) $B_{1}$ is a low-type consumer and she will sign up a low price; $B_{2}$ is a high-type consumer and she will sign up at a high price; $B_{1}$ is a high-type consumer and she will sign up at a low price; $B_{2}$ will sign up at a high price when she is a high-type consumer.

Form the incentive and compatibility condition:

$$
\begin{aligned}
\alpha\left(L-P_{L}\right)-(1-\alpha) P_{L} & \geq 0 \\
H-P_{H} & \leq \alpha\left(H-P_{L}\right)-(1-\alpha) P_{L} .
\end{aligned}
$$

Thus, $P_{L} \leq \alpha L, \quad(1-\alpha) H+\alpha L \leq P_{H} \leq H$. The expected profit is

$$
\pi_{K I A}^{M 2}=\alpha\left(P_{H}+P_{L}\right)=\alpha H+\alpha^{2} L
$$

(3) $B_{1}$ is a low-type consumer and she will not bid; $B_{1}$ will sign up at a high price when she is a high-type consumer, and $B_{2}$ will sign up at a low price.

Form the incentive and compatibility condition:

$$
\begin{aligned}
\alpha\left(L-P_{L}\right)-(1-\alpha) P_{L} & \leq 0, \\
H-P_{H} & \geq \alpha\left(H-P_{L}\right)-(1-\alpha) P, \\
H-P_{H} & \geq 0 .
\end{aligned}
$$


Thus, if $1 \leq H / L \leq 1 / \alpha$, we have $\alpha L \leq P_{L} \leq L, P_{H} \leq H$. The expected profit is $\pi_{K I A}^{M 3}=\left[\alpha^{2}+\alpha(1-\right.$ $\alpha)]\left(P_{H}+P_{L}\right)=\alpha(H+L)$; if $H / L \geq 1 / \alpha$, we have $\alpha L \leq P_{L} \leq L, P_{H} \leq(1-\alpha) H+\alpha L$, and the expected

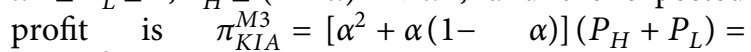
$\left(\alpha-\alpha^{2}\right) H+2 \alpha L$.

(4) $B_{1}$ is a low-type consumer and she will not bid; $B_{1}$ is a high-type consumer and will sign up at a low price, and $B_{2}$ will sign up at a high price when she is a hightype consumer.

Form the incentive and compatibility condition:

$$
\begin{aligned}
\alpha\left(L-P_{L}\right)-(1-\alpha) P_{L} & \leq 0 \\
H-P_{H} & \leq \alpha\left(H-P_{L}\right)-(1-\alpha) P_{L} .
\end{aligned}
$$

Thus, $\alpha L \leq P_{L} \leq L$ and $(1-\alpha) H+\alpha L \leq P_{H} \leq H$. The expected is $\pi_{K I A}^{M 4}=\alpha^{2}(H+L)$.

By comparing the expected profit we can get Proposition 1.

Proof of Proposition 2. From Table 2, by comparing the expected profit under the fixed mechanism and the expected profit under the flexible mechanism in each area, it is easy to get Proposition 2.

Proof of Proposition 3. Similar to Proposition 1, we analyze the profit under four situations.

(1) Form the incentive and compatibility condition:

$$
\begin{aligned}
H Q_{H}-P_{H} & \geq 0 \\
\alpha\left(L Q_{L}-P_{L}\right)-(1-\alpha) P_{L} & \geq 0 \\
H Q_{H}-P_{H} & \leq H Q_{L}-P_{L}, \\
H Q_{H}-P_{H} & \geq \alpha\left(H Q_{L}-P_{L}\right)-(1-\alpha) P_{L} .
\end{aligned}
$$

Thus, we have $P_{L} \leq \alpha L Q_{L}$ and $H Q_{H^{-}}$ $(H-\alpha L) Q_{L} \leq P_{H} \leq H Q_{H}-\alpha(H-L) Q_{L}$.

The expected profit is $\pi_{K I A}^{M}==\left(2 \alpha-\alpha^{2}\right)\left[H Q_{H}-\alpha\right.$ $\left.(H-L) Q_{L}+\alpha L Q_{L}-\left(Q_{H}^{2} / 2\right)-\left(Q_{L}^{2} / 2\right)\right]$.

Using the first order condition, we have $Q_{H}=H$ and $Q_{L}=\alpha(2 L-H)$.

(1) If $H / L \geq 2, \quad\left(Q_{H}, P_{H}\right)=\left(H, H^{2}\right), \quad\left(Q_{L}, P_{L}\right)=$ $(0,0)$, and $\pi_{K I A}^{M 1}=\left(\left(2 \alpha-\alpha^{2}\right) / 2\right) H^{2}$

(2) If $1 \leq H / L \leq 2, \quad\left(Q_{H}, P_{H}\right)=\left(H,\left(1+\alpha^{2}\right) H^{2}-\right.$ $\left.3 \alpha^{2} H L+2 \alpha^{2} L^{2}\right),\left(Q_{L}, P_{L}\right)=\left(\alpha(2 L-H), 2 \alpha^{2} L^{2}-\right.$ $\left.\alpha^{2} H L\right), \quad$ and $\pi_{K I A}^{M 2}=\left(2 \alpha-\alpha^{2} / 2\right)\left[\left(1+\alpha^{2}\right)\right.$ $\left.H^{2}-4 \alpha^{2} H L+4 \alpha^{2} L^{2}\right]$

(2) Form the incentive and compatibility condition:

$$
\begin{aligned}
H Q_{H}-P_{H} & \geq 0 \\
\alpha\left(L Q_{L}-P_{L}\right)-(1-\alpha) P_{L} & \geq 0 \\
H Q_{H}-P_{H} & \geq \alpha\left(H Q_{L}-P_{L}\right)-(1-\alpha) P_{L} .
\end{aligned}
$$

Thus, we have $P_{L} \leq \alpha L Q_{L}$ and $P_{H} \leq H Q_{H^{-}}$ $(H-\alpha L) Q_{L}$. The expected profit is

$$
\begin{aligned}
\pi_{K I A}^{M}==\alpha & {\left[2 H Q_{H}-2(H-\alpha L) Q_{L}-Q_{H}^{2}\right] } \\
& +\alpha(1-\alpha)\left[2 \alpha L Q_{L}-Q_{L}^{2}\right] .
\end{aligned}
$$

Using the first order condition, $\left(Q_{H}, P_{H}\right)=\left(H, H^{2}\right)$ and $\pi_{K I A}^{M 3}=\alpha H^{2}$.

(3) Form the incentive and compatibility condition:

$$
\begin{aligned}
H Q_{H}-P_{H} & \geq 0 \\
H Q_{H}-P_{H} & \leq \alpha\left(H Q_{L}-P_{L}\right)-(1-\alpha) P_{L}, \\
\alpha\left(L Q_{L}-P_{L}\right)-(1-\alpha) P_{L} & \geq 0 .
\end{aligned}
$$

Thus, we have $P_{L} \leq \alpha L Q_{L}$ and $H Q_{H}-\alpha(H-$ L) $Q_{L} \leq P_{H} \leq H Q_{H}$.

The expected $\pi_{K I A}^{M}==\alpha\left(H Q_{H}+\alpha L Q_{L}-\left(Q_{H}^{2} / 2\right)-\right.$ $\left.\left(Q_{L}^{2} / 2\right)\right)$.

Using the first condition, we have $Q_{H}=H$ and $Q_{L}=\alpha L$.

Thus, $\left(Q_{H}, P_{H}\right)=\left(H, H^{2}\right), \quad\left(Q_{L}, P_{L}\right)=\left(\alpha L, \alpha^{2} L^{2}\right)$, and $\pi_{K I A}^{M 4}=\alpha / 2\left(H^{2}+\alpha^{2} L^{2}\right)$.

(4) Form the incentive and compatibility condition:

$$
\begin{aligned}
\alpha\left(L Q_{L}-P_{L}\right)- & (1-\alpha) P_{L} \leq 0 \\
H Q_{H}-P_{H} & \geq H Q_{L}-P_{L} \\
H Q_{H}-P_{H} & \geq \alpha\left(H Q_{L}-P_{L}\right)-(1-\alpha) P_{L}
\end{aligned}
$$

Thus, we have $\alpha L Q_{L} \leq P_{L} \leq L Q_{L}$ and $P_{H} \leq H Q_{H^{-}}$ $(H-L) Q_{L}$, and the expected profit is

$$
\begin{aligned}
\pi_{K I A}^{M}== & \left(\alpha+\alpha^{2}\right)\left[H Q_{H}-(H-L) Q_{L}-\frac{Q_{H}^{2}}{2}\right] \\
& +\left(\alpha-\alpha^{2}\right)\left[L Q_{L}-\frac{Q_{L}^{2}}{2}\right] .
\end{aligned}
$$

Using the first order condition $Q_{H}=H$, $Q_{L}=(2 L-(1+\alpha) H) /(1-\alpha)$. 
(1) If $\quad 1 \leq H / L \leq 2 /(1+\alpha)\left(Q_{H}, P_{H}\right)=\left(H, \quad\left(2 H^{2}-\right.\right.$ $\left.\left.(3+\alpha) H L+2 L^{2}\right) /(1-\alpha)\right), \quad\left(Q_{L}, P_{L}\right)=((2 L-$ $\left.(1+\alpha) H) / \quad(1-\alpha),\left(2 L^{2}-(1+\alpha) H L\right) /(1-\alpha)\right)$, and $\quad \pi_{K I A}^{M 8}=(\alpha / 1-\alpha)\left[(\alpha+1) H^{2}-\right.$ $\left.(2 \alpha+2) H L+2 L^{2}\right]$

(2) If $H / L \leq 2 /(1+\alpha), \quad\left(Q_{H}, P_{H}\right)=\left(H, H^{2}\right)$, and $\left(Q_{L}, P_{L}\right)=(0,0), \pi_{K I A}^{M}=\left(\alpha+\alpha^{2} / 2\right) H^{2}$ tion 3 .

By comparing the expected profit, we can get Proposi-

Proof of Proposition 4. Similar to Proposition 1, we analyze the profit under the three situations.

(1) Form the incentive and compatibility condition, for consumer $B_{2}$ :

$$
\begin{aligned}
H Q_{H}-P_{H} & \geq 0, \\
L Q_{L}-P_{L} & \geq 0, \\
H Q_{H}-P_{H} & \leq H Q_{L}-P_{L} .
\end{aligned}
$$

For consumer $B_{2}$,

$$
\begin{aligned}
& H Q_{H}-P_{H} \geq \alpha\left(H Q_{L}-P_{L}\right), \\
& H Q_{H}-P_{H} \geq 0 .
\end{aligned}
$$

Thus, we have $P_{L} \leq L Q_{L}$ and $H Q_{H}-(H-L) Q_{L} \leq$ $P_{H} \leq H Q_{H}-\alpha(H-L) Q_{L}$.

The expected profit is

$$
\pi_{A O N}^{M}=\left[\alpha^{2}+2 \alpha(1-\alpha)\right]\left(P_{H}+P_{L}-\frac{Q_{H}^{2}}{2}-\frac{Q_{L}^{2}}{2}\right) .
$$

Using the first order condition, we have

(1) $1 \leq H / L \leq(1+\alpha) / \alpha, \quad\left(Q_{H}, P_{H}\right)=\left(H, H^{2}-\alpha(H-\right.$ $L))$, and $\left(Q_{L}, P_{L}\right)=\left((1+\alpha) L-\alpha H,(1+\alpha) L^{2}-\right.$ $\alpha H L)$.

The expected profit is $\pi_{A O N}^{M 1}=(\alpha(2-\alpha) / 2)[(1+$ $\left.\left.\alpha^{2}\right) H^{2}-2 \alpha(1+\alpha) H L+(1+\alpha)^{2} L^{2}\right]$.

(2) $H / L \geq(1+\alpha) / \alpha, \quad\left(Q_{H}, P_{H}\right)=\left(H, H^{2}\right), \quad\left(Q_{L}, P_{L}\right)=$ $(0,0)$, and $\pi_{A O N}^{M 1}=(\alpha(2-\alpha) / 2) H^{2}$.

(2) Form the incentive and compatibility condition, for consumer $B_{2}$ :

$$
\begin{aligned}
H Q_{H}-P_{H} & \geq H Q_{L}-P_{L}, \\
L Q_{L}-P_{L} & \geq 0,
\end{aligned}
$$

For consumer $B_{1}$,

$$
\begin{aligned}
& H Q_{H}-P_{H} \geq \alpha\left(H Q_{L}-P_{L}\right), \\
& H Q_{H}-P_{H} \geq 0 .
\end{aligned}
$$

Thus, $P_{L} \leq L Q_{L}$ and $P_{H} \leq H Q_{H}-(H-L) Q_{L}$.

The expected profit is

$$
\begin{aligned}
\pi_{A O N}^{M}= & 2 \alpha\left[H Q_{H}-(H-L) Q_{L}-\frac{Q_{H}^{2}}{2}\right] \\
& +\left(2 \alpha-2 \alpha^{2}\right)\left(L Q_{L}-\frac{Q_{L}^{2}}{2}\right) .
\end{aligned}
$$

Using the first order condition, we have $Q_{H}=H$ and $Q_{L}=((2-\alpha) L-H) / 1-\alpha$.

Thus,

(1) $1 \leq H / L \leq 2-\alpha,\left(Q_{H}, P_{H}\right)=\left(H,\left((2-\alpha) H^{2}+(\alpha-\right.\right.$ 3) $\left.\left.H L+\quad(2-\alpha) L^{2}\right) / 1-\alpha\right)$, and $\left(Q_{L}, P_{L}\right)=(((2-$ $\left.\alpha) L-H) /(1-\alpha),\left((2-\alpha) L^{2}-H L\right) /(1-\alpha)\right)$, and the optimal expected profit is

$$
\pi_{A O N}^{M 2}=\frac{\alpha(2-\alpha)}{1-\alpha}\left[H^{2}-2 H L+(2-\alpha) L^{2}\right] .
$$

(2) $H / L \geq 2-\alpha,\left(Q_{H}, P_{H}\right)=\left(H, H^{2}\right),\left(Q_{L}, P_{L}\right)=(0,0)$, and $\pi_{A O N}^{M 2}=\alpha H^{2}$.

(3) Form the incentive and compatibility condition, for consumer $B_{2}$ :

$$
\begin{aligned}
H Q_{H}-P_{H} & \geq 0, \\
L Q_{L}-P_{L} & \geq 0 .
\end{aligned}
$$

For consumer $B_{1}$,

$$
H Q_{H}-P_{H} \leq \alpha\left(H Q_{L}-P_{L}\right)
$$

Thus, $P_{L} \leq L Q_{L}$ and $H Q_{H}-\alpha(H-L) Q_{L} \leq P_{H} \leq H Q_{H}$. The expected profit is

$$
\begin{aligned}
\pi_{A O N}^{M} & =\left[\alpha^{2}+\alpha(1-\alpha)\right]\left(P_{H}+P_{L}-\frac{Q_{H}^{2}}{2}-\frac{Q_{L}^{2}}{2}\right) \\
& =\alpha\left(H Q_{H}+L Q_{L}-\frac{Q_{H}^{2}}{2}-\frac{Q_{L}^{2}}{2}\right) .
\end{aligned}
$$

Using the first order condition, we can get $Q_{H}=H$, $Q_{L}=L$, and $\pi_{A O N}^{M 3}=\alpha / 2\left(H^{2}+L^{2}\right)$.

By comparing the expected profit, we can get Proposition 4 .

Proof of Proposition 5. From Table 3, by comparing the expected profit under the fixed mechanism and the expected profit under the flexible mechanism in each area, it is easy to get Proposition 5. 


\section{Data Availability}

No data have been used in the research.

\section{Conflicts of Interest}

The authors declare that they have no conflicts of interest.

\section{Acknowledgments}

This work was supported by the Social Science Foundation (18BGL014).

\section{References}

[1] E. Mollick, "The dynamics of crowdfunding: an exploratory study," Journal of Business Venturing, vol. 29, no. 1, pp. 1-16, 2014.

[2] D. Cumming, G. Leboeuf, and A. Schwienbacher, "Crowdfunding models: keep-it-all vs. all-or-nothing," 2018, https:// ssrn.com/abstract $=2447567$.

[3] M. Mussa and S. Rosen, "Monopoly and product quality," Journal of Economic Theory, vol. 18, no. 2, pp. 301-317, 1978.

[4] K. S. Moorthy, "Market segmentation, self-selection, and product line design," Marketing Science, vol. 3, no. 4, pp. 288-307, 1984.

[5] J. M. Villas-Boas, "Product line design for a distribution channel," Marketing Science, vol. 17, no. 2, pp. 156-169, 1998.

[6] S. Balachander and K. Srinivasan, "Selection of product line qualities and prices to signal competitive advantage," Management Science, vol. 40, no. 7, pp. 824-841, 1994.

[7] P. S. Desai, "Quality segmentation in spatial markets: when does cannibalization affect product line design?" Marketing Science, vol. 20, no. 3, pp. 265-283, 2001.

[8] R. Thomadsen, "Seeking an expanding competitor: how product line expansion can increase all firms' profits," Journal of Marketing Research, vol. 49, no. 3, pp. 349-360, 2012.

[9] L. Guo and J. Zhang, "Consumer deliberation and product line design,” Marketing Science, vol. 31, no. 6, pp. 995-1007, 2012.

[10] A. Agrawal, C. Catalini, and A. Goldfarb, "Crowdfunding: geography, social networks, and the timing of investment decisions," Journal of Economics \& Management Strategy, vol. 24, no. 2, pp. 253-274, 2015.

[11] J. Chang, "The economics of crowdfunding," 2016, https:// papers.ssrn.com/sol3/papers.cfm?abstract_id=2585611.

[12] M. Hu, X. Li, and M. Shi, "Product and pricing decisions in crowdfunding," Marketing Science, vol. 34, no. 3, pp. 331-345, 2015.

[13] G. Bi, B. Geng, and L. Liu, "On the fixed and flexible funding mechanisms in reward-based crowdfunding," European Journal of Operational Research, vol. 279, no. 1, pp. 168-183, 2019.

[14] R. Strausz, "A theory of crowdfunding: a mechanism design approach with demand uncertainty and moral hazard," American Economic Review, vol. 107, no. 6, pp. 1430-1476, 2017.

[15] G. Chemla and T. Katrin, "Learning through crowdfunding," 2016, https://papers.ssrn.com/sol3/papers.cfm?abstract_ id $=2796435$.

[16] M. Lin and S. Viswanathan, "Home bias in online investments: an empirical study of an online crowdfunding market," Management Science, vol. 62, no. 5, pp. 1393-1414, 2015.
[17] G. Burtch, Y. Hong, and D. Liu, "On the role of provision points in online crowdfunding," Journal of Management Information System, vol. 35, no. 1, pp. 117-144, 2018.

[18] P. Belleflamme, T. Lambert, and A. Schwienbacher, "Crowdfunding: tapping the right crowd," Journal of Business Venturing, vol. 29, no. 5, pp. 585-609, 2014.

[19] N. Marwell, "Competing funding models in crowdfunding markets," 2015, https://papers.ssrn.com/sol3/papers.cfm? abstract_id=2777020. 